\title{
Distinct Retinal Deficits in a Zebrafish Pyruvate Dehydrogenase-Deficient Mutant
}

\author{
Colette M. Maurer, Helia B. Schönthaler, Kaspar P. Mueller, and Stephan C. F. Neuhauss \\ University of Zurich, Institute of Molecular Life Sciences, Neuroscience Center Zurich and Center for Integrative Human Physiology, CH-8057 Zurich, \\ Switzerland
}

\begin{abstract}
Mutations in ubiquitously expressed metabolic genes often lead to CNS-specific effects, presumably because of the high metabolic demands of neurons. However, mutations in omnipresent metabolic pathways can conceivably also result in cell type-specific effects because of cell-specific requirements for intermediate products. One such example is the zebrafish noir mutant, which we found to be mutated in the $p d h b$ gene, coding for the E1 $\beta$ subunit of the pyruvate dehydrogenase complex. This vision mutant is described as blind and was isolated because of its vision defect-related darker appearance. A detailed morphological, behavioral, and physiological analysis of the phenotype revealed an unexpected specific effect on the retina. Surprisingly, the cholinergic amacrine cells of the inner retina are affected earlier than the photoreceptors. This might be attributable to the inability of these cells to maintain production of their neurotransmitter acetylcholine. This is reflected in an earlier loss of motion vision, followed only later by a general loss of light perception. Since both characteristics of the phenotype are attributable to a loss of acetyl-CoA production by pyruvate dehydrogenase, we used a ketogenic diet to bypass this metabolic block and could indeed partially rescue vision and prolong survival of the larvae. The noir mutant provides a case for a systemic disease with ocular manifestation with a surprising specific effect on the retina given the ubiquitous requirement for the mutated gene.
\end{abstract}

\section{Introduction}

Mutations in genes encoding mitochondrial proteins often preferentially affect tissue with high energy demand (Wallace, 1999), in particular the CNS with its neurons being among the most energy-demanding cells of the animal body. This is notably true for the retina with its mitochondrium-rich photoreceptors being among the most metabolically active cells of the vertebrate body (Ames et al., 1992; Laughlin, 2001; Okawa et al., 2008). The study of such metabolic diseases is often hampered by early embryonic lethality in mammals. A case in point is targeted disruption of subunits of the murine pyruvate dehydrogenase (PDH) complex that links glycolysis with the Krebs [tricarboxylic acid (TCA)] cycle. These mice show early embryonic lethality and their use to study effects on the nervous system is very limited (Johnson et al., 1997, 2001). This constraint can be overcome in the zebrafish model. Since early embryogenesis is supported by maternally supplied mRNA and proteins, the mutants are not embryonically lethal. Hence the effect of zygotic mutations affecting basic metabolism can be studied on later developing structures including the nervous system.

\footnotetext{
Received June 4, 2010; revised July 12, 2010; accepted July 15, 2010.

This work was supported by the European Commission as part of the RETICIRC program, and the Swiss National Science Foundation. We thank Dr. Robert Geisler and Ines Gehring for assistance with genomic mapping, Kerstin Dannenhauer for assistance with cell quantification, and Dr. Breandan Kennedy for the fli1:EGFP line.

Correspondence should be addressed to Prof. Dr. Stephan C. F. Neuhauss, Institute of Molecular Life Sciences, University of Zurich, Winterthurerstrasse 190,CH-8057Zurich, Switzerland. E-mail:stephan.neuhauss@imls.uzh.ch.

H. B. Schönthaler's present address: BBVA Foundation-Cancer Cell Biology Programme, Spanish National Cancer Research Centre, E-28029 Madrid, Spain.

DOI:10.1523/JNEUROSCI.2848-10.2010

Copyright $\odot 2010$ the authors $\quad$ 0270-6474/10/3011962-11\$15.00/0
}

As part of a large-scale screen to isolate chemically induced mutations affecting embryogenesis, two alleles of the mutant noir have been isolated because of their expanded melanophores giving an overall darker appearance (Kelsh et al., 1996). This mutant was shown to be blind in subsequent behavioral and physiological experiments (Neuhauss et al., 1999). To decipher the underlying molecular defect in this mutant, we performed positional cloning. This revealed a mutation in the gene coding for the E1 $\beta$ subunit of the pyruvate dehydrogenase complex ( $p d h b)$. A mutant defective in the E2 subunit of the same complex has been linked to the noa (no optokinetic response a) mutant, which was similarly identified in a screen for mutants affected in visual behavior (Brockerhoff et al., 1995, 1998; Taylor et al., 2004). Mutations in this complex cause Leigh's syndrome in humans (Quintana et al., 2009), a progressive neurometabolic disorder characteristic of focal, bilateral lesions in one or more areas of the CNS (Leigh, 1951; McKusick et al., 1986).

We investigated the retinal defect in the noir mutant in more detail and found defects both in the outer retina and in cholinergic amacrine cells of the inner retina. Intriguingly, different aspects of vision are differentially affected. Motion vision, the basis of the visual behavior used to identify both mutants, is earlier affected than general light perception. Larvae lose their response to motion stimuli before they lose vision in general, as demonstrated by electroretinography and visual behavior experiments. We propose a metabolic model that may account for the selective deficit of cholinergic cells. Providing the mutant larvae with a ketogenic diet to bypass the requirement of acetyl-CoA production by pyruvate dehydrogenase partially rescues the phenotype and enhances survival of mutant larvae. 
The noir mutant provides an example for a systemic disease with ocular manifestation with a surprisingly specific effect on the retina given the ubiquitous requirement of the mutated gene.

\section{Materials and Methods}

Fish maintenance. Zebrafish (Danio rerio) were maintained under standard conditions (Brand et al., 2002). The noir (nir ${ }^{t c 22}$ and nir ${ }^{\text {tp89 }}$ ) mutation was kept in heterozygous fish, which were crossed to obtain homozygous noir larvae. Larvae were kept at $28^{\circ} \mathrm{C}$ in $\mathrm{E} 3$ embryo medium $\left(5 \mathrm{~mm} \mathrm{NaCl}, 0.17 \mathrm{~mm} \mathrm{KCl}, 0.33 \mathrm{~mm} \mathrm{CaCl}, 0.33 \mathrm{~mm} \mathrm{MgSO}_{4}, 10^{-5} \%\right.$ methylene blue). Strains used in this study were as follows: Tuebingen (Tue) (Haffter et al., 1996), WIK (Dahm et al., 2005), nir ${ }^{\text {tc22 }}$ and nir ${ }^{\text {tp89 }}$ (Kelsh et al., 1996), and TG(fli1:EGFP) (Lawson and Weinstein, 2002).

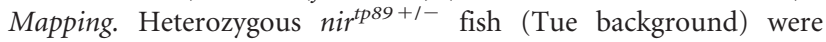
crossed to wild-type fish of the WIK strain, and from the offspring of these crosses homozygous noir larvae and siblings were separated and collected. Forty-eight nir $^{\text {tp } 89-1-}$ larvae as well as 48 siblings were used to perform bulked segregant analysis using 192 single sequence length polymorphism (SSLP) markers distributed over the whole genome. Additional fine mapping was performed using the total DNA of single homozygous mutant larvae. DNA extraction and PCR were performed as described previously (Geisler, 2002). Fine mapping was performed using the total DNA of 720 single ir $^{\text {tp } 89-/-}$ larvae.

Western blot. For protein lysates, 30 larvae of each condition were collected and stored at $-80^{\circ} \mathrm{C}$. One hundred microliters of lysis buffer (50 mм Tris-HCl, pH 7.5, 150 mм NaCl, 1 mм DTT, 1 mм EDTA, pH 8, $10 \%$ glycerol, $1 \%$ Triton X-100) per 30 larvae were added, and the mix was sonificated and centrifuged. Supernatant was used for the remaining procedure. Protein concentration was determined using the DC Protein Assay kit (Bio-Rad).

Western blot was performed using a monoclonal mouse anti-human PDHB antibody (Abcam; ab55574) in a 1:2000 dilution and a HRPconjugated goat anti-mouse antibody (Thermo Fisher Scientific) for detection. Immunoblots were developed with the ECL system (Super Signal West; Thermo Fisher Scientific).

Reverse transcription-PCR. Total RNA was isolated from 20 eggs of the one-cell stage using the RNAeasy kit (QIAGEN). RNA was reverse transcribed using the SuperScript RTII kit (Invitrogen) and oligo-dT primers. For PCR amplification, a forward primer (TACAGAGGACAGTGAAACATGG) and a reverse primer (ATTGTGTCCGGATGGAGG) and an annealing temperature of $60^{\circ} \mathrm{C}$ were used to amplify a part of the PDHE1 $\beta$ gene. A part of the $\beta$-actin gene was coamplified using the forward primer AAG CAG GAG TAC GAT GAG TCT G and the reverse primer GGT AAA CGC TTC TGG AAT GAC. Amplification products were visualized on a $1 \%$ agarose gel containing ethidium bromide.

Histology. Larvae were fixed in 4\% paraformaldehyde (PFA) (paraformaldehyde in phosphate buffer, $\mathrm{pH} 7.4$ ) overnight at $4^{\circ} \mathrm{C}$. After dehydration in a graded series of ethanol-water mixtures, larvae were incubated in a 1:1 and then 1:3 ethanol Technovit 7100 (Heraeus Kulzer) solution for $1 \mathrm{~h}$. After infiltration in the Technovit solution, overnight larvae were embedded in Technovit 7100 polymerization medium and dried at $37^{\circ} \mathrm{C}$ for $1 \mathrm{~h}$. Three-micrometer-thick sections were prepared with a microtome, mounted onto Superfrost slides (Thermo Fisher Scientific), and dried at $60^{\circ} \mathrm{C}$. Richardson (Romeis) staining ( $0.5 \%$ borax, $0.5 \%$ Azur II, $0.5 \%$ methylene blue) was performed and the slides were mounted in Entellan (Merck).

A BX61 microscope (Olympus) was used for imaging the slides in the bright-field modus.

Immunohistochemistry. Paraformaldehyde-fixed larvae (4\% PFA in phosphate buffer, $\mathrm{pH} 7.4$ ) were cryoprotected in $30 \%$ sucrose in PBS overnight at $4^{\circ} \mathrm{C}$ and were embedded in cryomatrix (TissueTek OCT compound; Sakura Finetek) using liquid $\mathrm{N}_{2}$ to immediately freeze the samples. Sections of $20 \mu \mathrm{m}$ were prepared at $-18^{\circ} \mathrm{C}$ using a cryostat and were mounted onto Superfrost slides (Thermo Fisher Scientific). Slides were air dried at room temperature (RT) and stored at $-20^{\circ} \mathrm{C}$. Before use, slides were thawed at $37^{\circ} \mathrm{C}$ for $30 \mathrm{~min}$ and washed in PBS, pH 7.4, for
10 min. Blocking solution (10\% normal goat serum, $1 \%$ bovine serum albumine, $0.3 \%$ Tween 20 in PBS, pH 7.4) was applied for at least $2 \mathrm{~h}$ at $\mathrm{RT}$, and primary antibodies diluted in blocking solution were incubated overnight at $4^{\circ} \mathrm{C}$. The following antibodies were used: mouse antiglutamine synthase (Millipore Bioscience Research Reagents; MAB302), 1:700; rabbit anti-cPKC $\beta$ I (C-16) (Santa Cruz; sc-209), 1:150; rabbit anti-tyrosine hydroxylase (TH) (Millipore; AB152), 1:1000; goat anticholine acetyltransferase (ChAT) (Millipore; AB144P), 1:100; rabbit anti-serotonin, 5-hydroxytryptamine (5-HT) (Sigma-Aldrich; S5545), 1:1000; mouse anti-parvalbumin (Millipore; MAB1572), 1:1000; mouse anti-PCNA (proliferating cell nuclear antigen) (clone: PC10; Zymed Laboratories), 1:150; and rabbit anti-caspase 3 (557038; BD Biosciences), 1:200. For ChAT immunolabeling, the normal goat serum was omitted from the blocking solution.

The immunoreaction was then detected using fluorescently labeled secondary antibodies (Alexa Fluor 488 goat anti-rabbit, Alexa Fluor 568 goat anti-mouse, Alexa Fluor 488 donkey anti-goat; all from Invitrogen) diluted 1:1000 in PBS.

Slides were coverslipped and imaged in a BX61 microscope (Olympus) using the appropriate filter.

Cell quantification. $z$-stacks within a $z$-distance of $20 \mu \mathrm{m}$ and a sequential distance of $1 \mu \mathrm{m}$ were recorded using a BX61 microscope (Olympus) and the Cell-F software (Olympus Soft Imaging Solutions). Maximumintensity projections were generated and were used for cell counting.

At least six animals per condition were used for quantification. With the help of WCIF ImageJ cell counter plug-in software (National Institutes of Health, Bethesda, MD), stained cells were counted and data were analyzed with the GraphPad Prism 4.00 software (GraphPad Software). For cell quantification of the ganglion cell layer, histologically stained sections were used. Cells in a segment of $60^{\circ}$ with its origin in the center of the lens and one arm in close proximity along the optic nerve were counted and evaluated. Cell counts of both eyes of a fish were averaged, resulting in one data point per animal.

Electroretinogram. Electroretinograms (ERGs) were recorded as described previously (Makhankov et al., 2004). Briefly, larvae were dark adapted for $30 \mathrm{~min}$ before recording. Then, the animal was placed on a sponge soaked with blank E3 medium ( $5 \mathrm{~mm} \mathrm{NaCl}, 0.17 \mathrm{~mm} \mathrm{KCl}, 0.33$ $\mathrm{mm} \mathrm{CaCl}, 0.33 \mathrm{~mm} \mathrm{MgSO}_{4}$ ) and the recording electrode with a tip diameter of $20 \mu \mathrm{m}$ filled with $\mathrm{E} 3$ was placed on the cornea while the reference electrode was beneath the animal. Stimuli of $100 \mathrm{~ms}$ with interstimulus intervals of $5 \mathrm{~s}$ were applied to elicit an ERG response. The light stimulus intensity was 5600 lux or $60 \mathrm{~W} / \mathrm{m}^{2}$.

For measuring the a- and d-wave, the b-wave was blocked by incubating the animal in $100 \mu \mathrm{M} \mathrm{APB} \mathrm{(L-AP-4)} \mathrm{(Tocris} \mathrm{Bioscience)} \mathrm{and} 200 \mu \mathrm{M}$ DL-threo- $\beta$-benzyloxyaspartic acid (TBOA) (Tocris Bioscience) (Wong et al., 2004) in E3 medium for 10-30 min before recording. No dark adaptation was performed when a- and d-wave were measured, and a stimulus duration of $1 \mathrm{~s}$ was used to separate both waves in time.

Optokinetic response. Zebrafish larvae were immobilized in prewarmed $3 \%$ methylcellulose as described previously (Rinner et al., 2005). Vertical black-and-white sine wave gratings were projected onto the inside of a white paper drum $(d=9 \mathrm{~cm})$ (Mueller and Neuhauss, 2010). The pattern was rotating around the restrained larva placed in the middle of the paper drum at an angular velocity of $7.5 \%$, changing the direction with a frequency of $0.3 \mathrm{~Hz}$. Contrast was varied between 0.05 and 1 , starting with the highest contrast, followed by a stepwise reduction to the lowest contrast, after which contrast was increased again to 1 . In this way, every contrast (except 0.05 ) was presented two times for $9 \mathrm{~s}$ each. Before measurements were initiated, the eyes were prestimulated for $9 \mathrm{~s}$ with a contrast of 0.99 . The eyes of the larvae were detected by custom-made software based on Lab View 7.1 and NI-IMAQ 3.7 (National Instruments) (Mueller and Neuhauss, 2010). Angular position of the eyes was determined at 5 frames per second and angular velocity of each eye was calculated in real time. Postexperimental data processing and analysis were conducted as described by Rinner et al. (2005). Graphs were generated using PASW Statistics 17.0 (SPSS).

Visual motor response. A similar setup as described by Emran et al. (2008) was used to measure the visual motor response (VMR). Larvae were placed in individual wells of a 96-well plate (7701-1651; Whatman) 
containing E3 medium. Mutants and siblings were arranged in a checkerboard manner to avoid positional effects. The wells were illuminated from below with an array of 36 infrared (IR)-emitting diodes $\left(\lambda_{\text {peak }}=880 \mathrm{~nm}\right)$ shielded by a diffuser. In addition to the IR diodes, the array contained $36 \mathrm{UV}\left(\lambda_{\text {peak }}=361 \mathrm{~nm}\right)$, blue $\left(\lambda_{\text {peak }}=435 \mathrm{~nm}\right)$, cyan $\left(\lambda_{\text {peak }}=500\right.$ $\mathrm{nm})$, and red $\left(\lambda_{\text {peak }}=630 \mathrm{~nm}\right)$ lightemitting diodes (LEDs) each. The brightness of each color could be controlled by a pulsewidth modulator (PWM83; National Control Devices) connected to the serial port of a computer. The larvae were monitored from above using an infrared sensitive CCD-camera (Pike F-032B; Allied Vision Technologies) equipped with a zoom lens (C6Z1218-FA; Pentax) fitted with an IR-pass filter (IF-093-SN1-49; Schneider Kreuznach).

Each larva was individually detected and tracked by custom-made software based on LabView 7.1 and NI-IMAQ 3.7 (National Instruments). Swimming speed of each larva was calculated in real time at 20 frames per second, averaged over periods of $1 \mathrm{~s}$, and written to disk every second.

The larvae's movements were tracked during a period of $7 \mathrm{~h}$ while changing the illumination. An initial period of $2 \mathrm{~h}$ darkness (IR illumination only) was applied to adapt and synchronize the larvae. Subsequently, all UV, blue, cyan, and red LEDs were simultaneously switched on and off in intervals of $30 \mathrm{~min}$. After the experiment, an empirically derived threshold was used to recode swimming speed of each larva into a binary activity measure. $\mathrm{R}$, version 2.9.2 (www.r-project.org), was used to plot the average activity of 48 larvae.

Phototaxis. An upturned computer screen was used to perform the phototaxis experiment. Two different assays were performed: in the first one, the screen was divided into three compartments, which were colored black-whiteblack. In between measurements, colors were reversed to redistribute the larvae. Twenty larvae were measured four times $1 \mathrm{~min}$ each, with 1 min redistribution intervals. The numbers of larvae in the white compartment were counted (data not shown).

In the second assay, the screen was divided into a black and a white compartment of equal sizes. A total of 20 larvae was placed in the dark compartment, and after every minute larvae in the white compartment were counted.

Ketogenic diet. The ketogenic diet mixture was prepared similarly to the one described by Taylor et al. (2004). Briefly, $10 \mathrm{~mm}$ stock solutions of lauric acid, myristic acid, palmitic acid, and phosphatidyl choline (all from SigmaAldrich) were prepared in E3 medium and solubilized in a sonification bath. A final diet mixture was prepared in E3 medium containing $100 \mu \mathrm{M}$ lauric acid, $100 \mu \mathrm{M}$ myristic acid, $200 \mu \mathrm{M}$ palmitic acid, and $500 \mu \mathrm{M}$ phosphatidyl choline, in which larvae were raised.

\section{Results}

The noir (nir) mutant was originally identified in a large-scale mutagenesis screen because of its darker appearance (Kelsh et al.,

A

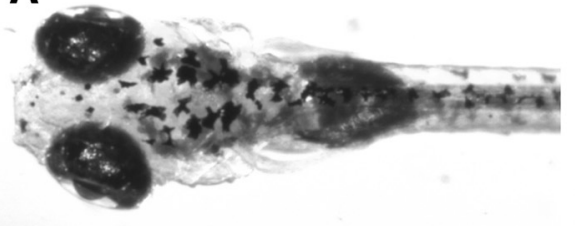

B
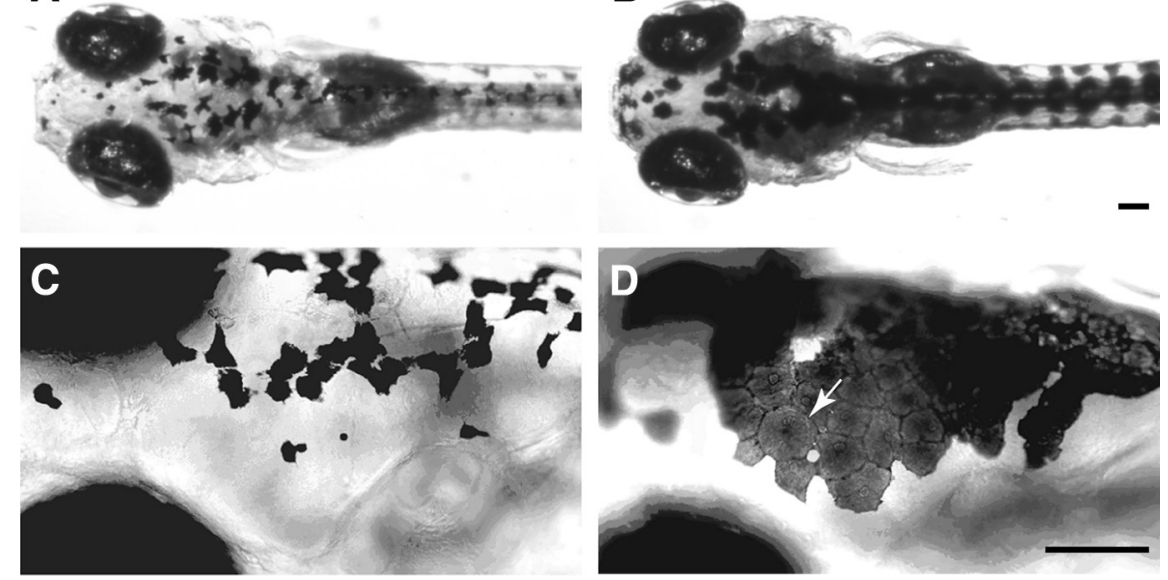

Figure 1. External phenotype of noir mutant larvae. Bright-field images of 5-d-old siblings and homozygous noir mutants. $A, C$, Sibling $5 \mathrm{dpf}$. B, D, noir mutant $5 \mathrm{dpf}$. noir mutants display expanded melanophores (arrow) compared with siblings, indicating defective background adaptation. Scale bar, $100 \mu \mathrm{m}$.
A

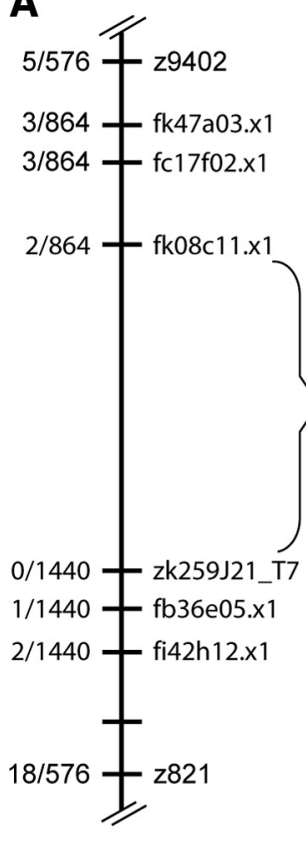

B Transketolase Domain central region
C

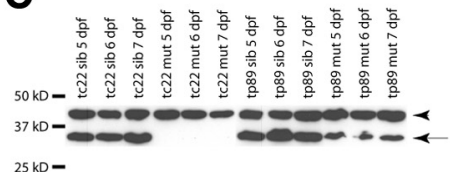

$25 \mathrm{kD}-$
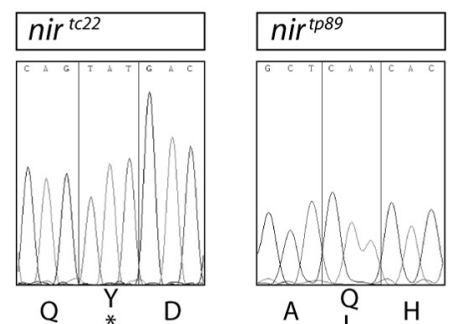

$\mathrm{RDH} 1$

Gls
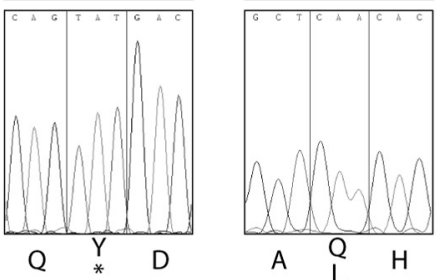

PDHE1 $\beta$

RPP14

TBC1

TBC1
Bloc1S1
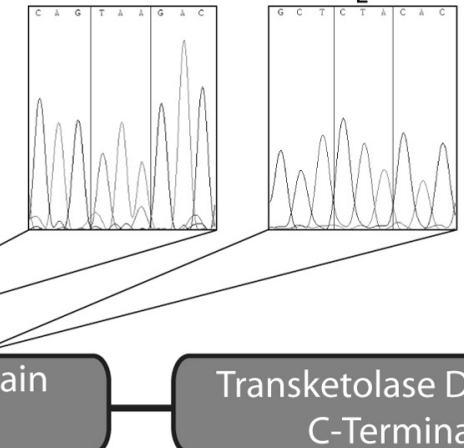

Transketolase Domain C-Terminal

Figure 2. noir is mutated in the pyruvate dehydrogenase subunit $\mathrm{E} 1 \beta(p d h b)$ gene. $A$, Schematic representation of the genomic region that contains the noir mutation. Genetic mapping established linkage to SSLP markers z9402 and z821 on chromosome 22. Recombination events (recombination events per number of meioses) are indicated on the left. ESTs that were used as SNP markers are indicated on the right. Three candidate genes (in black font) located within the narrowed area were cloned and analyzed for mutations. $\boldsymbol{B}$, Schematic drawing of the $p d h b$ gene (adapted from Pfam) showing the two transketolase domains. Sequence traces showing the location of the ir $^{\text {tc22 }}$ mutation (Y63X) and nir ${ }^{\text {tp89 }}$ mutation (Q157L) are depicted. C, Western blot with an anti-human PDHB antibody binding to an unknown epitope located between amino acids 250 and 360 . The zf-Pdhb protein was detected at the predicted molecular weight (arrow), and additionally, an unspecific protein was detected (arrowhead), which serves as an internal loading control.

1996). Expanded melanophores causing the darker appearance in noir and many other visually impaired mutants are an indication of blindness caused by lack of background adaptation (Fig. 1). Subsequent behavioral and electrophysiological analyses established that these mutants are unable to follow moving stripes 
with their eyes and having a defective ERG, confirming blindness (Neuhauss et al., 1999). Two alleles of the noir mutation (tp89a and $t c 22$ ) were identified with indistinguishable phenotype. Complementation crossings yielded a mendelian inheritance pattern confirming that the noir ${ }^{\text {tp } 89 a}$ and the noir ${ }^{t c 22}$ mutation are allelic.

Homozygous noir mutant larvae do not display an overt phenotype until $4 \mathrm{~d}$ postfertilization (dpf). At $5 \mathrm{dpf}$, expanded melanophores and a reduced baseline motility are observed (see Fig. 7A). The larvae remain mostly in a lateral resting position on the surface of the water, as the swimbladder is inflated. However, when startled, mutant larvae display a short but normal swimming behavior, indicating that muscles are unlikely to be directly affected in the mutant. At $\sim 7 \mathrm{dpf}$, mutant larvae die.

\section{noir carries a mutation in the pyruvate dehydrogenase subunit E1 $\boldsymbol{\beta}(\boldsymbol{p d h b})$ gene}

To identify the mutated gene underlying the noir phenotype, we performed positional cloning. We tested 192 SSLP markers distributed over the whole genome in a bulked segregant analysis using nir ${ }^{t p 89}$ mutants. By this, we were able to locate the mutation between markers z9402 and z821 on chromosome 22 (Geisler, 2002).

To narrow the critical interval further down, we used a number of expressed sequence tag (EST) sequences, which were mapped to the same genomic interval to test for single-nucleotide polymorphism (SNP) markers. By performing a chromosomal walk, we were able to identify a critical interval of $\sim 1.3$ centimorgan between markers fk08c11.x1 and zk259j21_T7 by recombination analysis (Fig. $2 \mathrm{~A}$ ). A number of candidate genes from this region were identified and cloned from affected and unaffected sibling larvae. Sequencing of these candidate genes revealed a point mutation in the gene coding for subunit E1 $\beta$ of the pyruvate dehydrogenase complex (PDHB) in the nir $^{t p 89}$ allele, leading to an exchange of a conserved glutamine to leucine at position 157. Additional sequencing of nir $^{\text {tc22 }}$ cDNA identified a point mutation resulting in a premature stop codon at position 63 , confirming that the mutation underlying the noir phenotype is in the $p d h b$ gene (Fig. $2 B$ ).

The nonsense mutation in $n$ ir $^{t c 22}$ is most likely amorphic, as is the missense mutation in nir $^{t p 89}$ given the identical phenotype.

To study the effect of the mutation on the protein level, we used a commercially available monoclonal antibody against a small fragment of the human PDHB protein in a Western blot analysis. We detected two bands in lysates of wild-type zebrafish larvae, a higher molecular weight unspecific band (used as an internal loading control) and a lower specific band of the predicted molecular weight.

Homozygous noir larvae of the $t c 22$ allele bearing the premature stop codon are completely devoid of Pdhb protein at all analyzed stages $(5,6$, and $7 \mathrm{dpf})$, arguing that any residual maternally supplied protein is used up by the time the phenotype becomes apparent (Fig. 2C).

Homozygous noir larvae of the tp89 allele exhibiting an amino acid exchange at position 157 of the amino acid sequence do maintain the Pdhb protein, although at reduced levels. Since there is no difference in the severity of phenotype between the two alleles, we conclude that the phenotype in this allele is caused by a nonfunctional protein rather than by diminished protein levels. The glutamine at position 157 is conserved in all species surveyed (from yeast to human), supporting a crucial functional role of this residue.
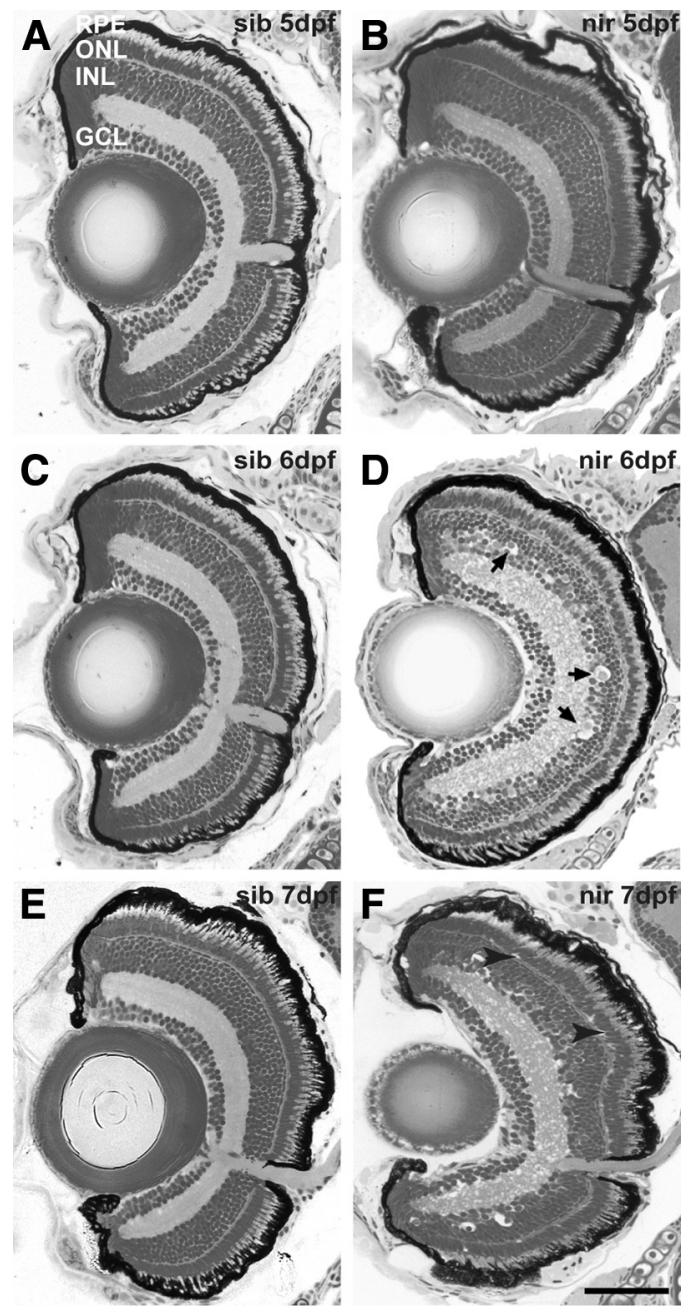

Figure 3. Standard retinal histology. $\boldsymbol{A}-\boldsymbol{F}$, Radial sections of the eye stained with Richardson (Romeis) solution show the appearance of wholes in the mutant inner retina at $6 \mathrm{dpf}$ (arrows) and in the outer retina at $7 \mathrm{dpf}$ (arrowheads). Shown are $5 \mathrm{dpf} \operatorname{sibling}(\boldsymbol{A}), 5 \mathrm{dpf}$ noir mutant $(\boldsymbol{B})$, $6 \mathrm{dpf}$ sibling $(\boldsymbol{C}), 6 \mathrm{dpf}$ noir mutant $(\boldsymbol{D}), 7 \mathrm{dpf}$ sibling $(\boldsymbol{E})$, and $7 \mathrm{dpf}$ noir mutant $(\boldsymbol{F})$. RPE, Retinal pigment epithelium; $0 \mathrm{NL}$, outer nuclear layer; INL, inner nuclear layer; $\mathrm{GCL}$, ganglion cell layer. Scale bar, $50 \mu \mathrm{m}$.

As it is remarkable that a mutation in a key metabolic enzyme such as the PDH complex is compatible with life and development of a zebrafish larvae up to $7 \mathrm{~d}$, we hypothesized that embryonic stages are supported by maternally deposited $p d h b$ mRNA or protein. We therefore isolated total mRNA from wild-type zebrafish eggs at the one-cell stage, before zygotic transcription starts, and reverse transcribed it into cDNA. We succeeded in amplifying $p d h b$-specific fragments, indicating that $p d h b$ mRNA is maternally deposited in the embryo (data not shown). Presumably, this maternal mRNA is translated into functional Pdhb protein, supporting embryogenesis.

\section{noir mutant larvae exhibit morphological alterations in} the retina

To assess retinal morphology of the noir larvae, we performed standard histology of the retina. Histological sections of 5-d-old noir retina did not show any morphological alterations when compared with wild-type retinae. At $6 \mathrm{dpf}$, histology revealed gaps in the inner nuclear layer (INL) of the noir retina, whereas there was no significant reduction in cell counts of the ganglion cell layer (GCL) (supplemental Fig. 1, available at www.jneurosci. 
org as supplemental material). Retinal morphology of noir larvae at $7 \mathrm{dpf}$ is dramatically altered compared with wild type, as degeneration is extended to the photoreceptor cell layer (Fig. 3).

Surprisingly, retinal damage in the noir retina is first observed in cells of the inner nuclear layer and not photoreceptors, as would be expected from a mutation in a key metabolic enzyme, given that photoreceptors are the most energy-consuming cells of the retina (Steinberg, 1987). A possible explanation could be that the alterations in the inner retina are attributable to abnormal blood vessels invading the retina. In the mammalian retina, hypoxia can induce abnormal sprouting of blood vessels into the inner retina (Gariano and Gardner, 2005; Kubota and Suda, 2009). Recently, hypoxia-induced retinal angiogenesis has also been shown to occur in the zebrafish (Cao et al., 2008; van Rooijen et al., 2010). We reasoned that reduced energy availability might mimic oxygen depletion. To test this hypothesis, we analyzed the retinal vasculature, by crossing the noir mutant into the transgenic fli1:EGFP line, which exhibits fluorescently labeled blood vessels (Lawson and Weinstein, 2002). We performed a histological analysis using antibodies against the GFP transgene and found no evidence for abnormal sprouting of either choroidal or hyaloid vessels in the mutant (data not shown). These experiments showed that the retinal phenotype of noir is unrelated to changes in the blood supply.

To further locate the defect in the mutant inner retina, we surveyed a number of different cell types of the inner retina. Markers for Müller glia cells (glutamine synthetase) and bipolar cells (cPKC $\beta$ ) revealed no alterations both in cell counts and cellular morphology (data not shown).

Since the motion-based optokinetic response (OKR) assay shows deficits before overall changes in retinal morphology are apparent, we assessed whether cholinergic amacrine cells are altered. In the mammalian retina, these cells, also called Starburst amacrine cells, are known to give input to directionselective ganglion cells (DSGCs) and are crucial for motion detection and direction selectivity (Yoshida et al., 2001; Vaney and Taylor, 2002; Masland, 2005; Demb, 2007; Zhou and Lee, 2008).

We therefore quantified cholinergic amacrine cells of 5-, 6-, and 7-d-old noir retinas by immunostaining of ChAT, a cholinergic amacrine cell-specific marker in the retina (Yazulla and Studholme, 2001). In the sibling retina, the cell count increases with development, whereas in the mutant the count is lower at 5 $\mathrm{dpf}$, which becomes statistically significant at later stages $(5 \mathrm{dpf}$ sib, $19.53 \pm 1.1$; mut, $16.74 \pm 0.34 ; p>0.05 ; 6 \mathrm{dpf}$ sib, $22.39 \pm$ 0.68 ; mut, $18.50 \pm 1.0 ; p<0.05 ; 7 \mathrm{dpf}$ sib, $26.10 \pm 2.5$; mut,
$21.30 \pm 0.9 ; p<0.05$ ) (Fig. 4). Displaced ChAT-positive amacrine cells in the GCL were not reliably quantifiable in our hands.

To determine whether the reduction is specific for cholinergic amacrine cells, we additionally investigated other types of amacrine cells in the noir retina that have their cell nuclei at similar locations than cholinergic cells. With the help of different markers for amacrine cells (Avanesov et al., 2005; Yeo et al., 2009), serotonergic (5-HT-positive), dopaminergic (THpositive), and parvalbumin-positive amacrine cells were quantified. No difference between amacrine cells of the noir and their sibling retinas was found at $5 \mathrm{dpf}$. At $6 \mathrm{dpf}$, however, the only significant difference between mutants and siblings was found in cholinergic amacrine cell counts. A general reduction of amacrine cells occurs at $7 \mathrm{dpf}$, pointing to a cell-unspecific effect at this stage (Fig. 4). 

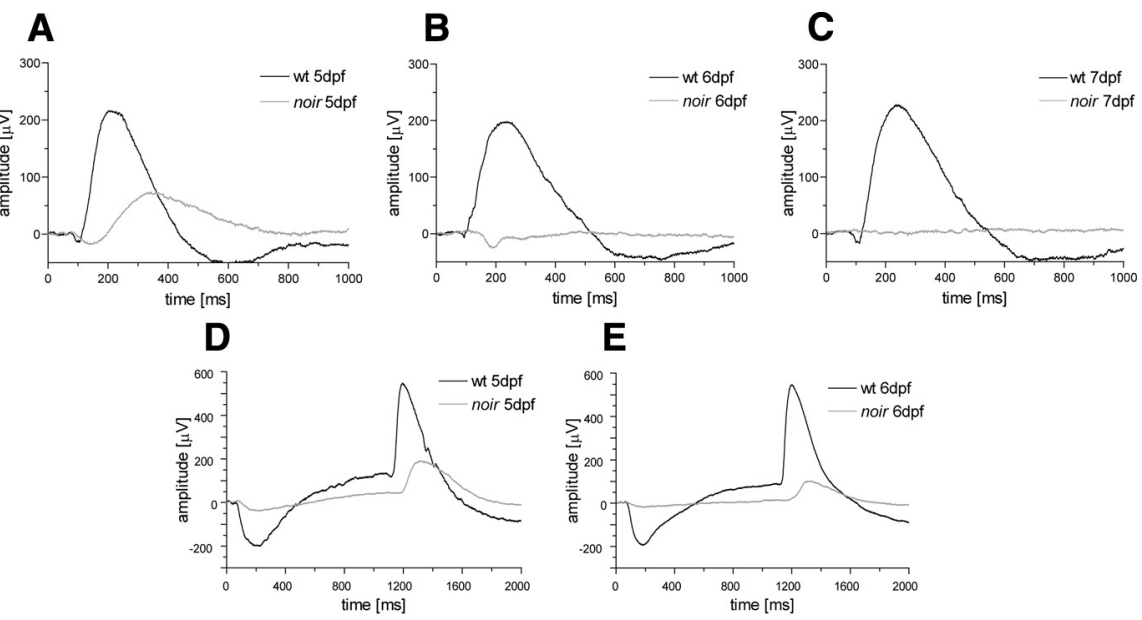

E
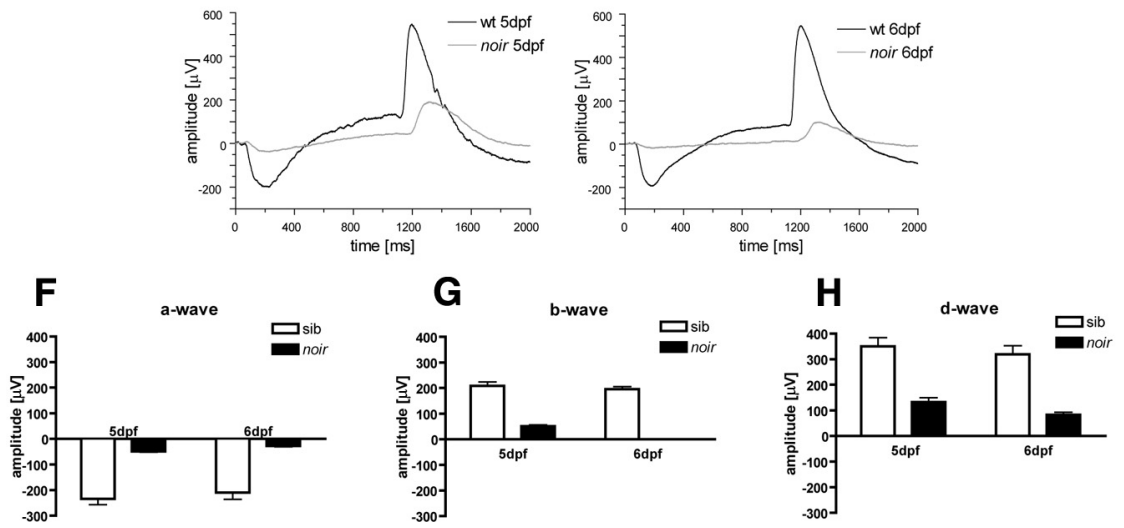

Figure 5. Electroretinography. A-C, Typical ERG traces of siblings and noir mutants are shown. A stimulus of 5600 lux for $100 \mathrm{~ms}$ was used to elicit saturated responses. $\boldsymbol{A}$, noir mutant and sibling at $5 \mathrm{dpf}$. $\boldsymbol{B}$, noir mutant and sibling at $6 \mathrm{dpf}$. $\boldsymbol{C}$, noir mutant and sibling at $7 \mathrm{dpf}$. D, E, ERG traces of siblings and mutants with blocked ON responses (100 $\mu$ M APB and $200 \mu \mathrm{M}$ TBOA). Stimulus of 5600 lux for $1 \mathrm{~s}$ was used to elicit saturated responses. $\boldsymbol{D}$, noir and sibling at $5 \mathrm{dpf}$. $\boldsymbol{E}$, noir and sibling at $6 \mathrm{dpf}$. $\boldsymbol{F}-\boldsymbol{H}$, Graphs depicting average amplitudes (means of $n \geq 10 \pm$ SEM) of noir mutants and siblings. $\boldsymbol{F}$, a-wave amplitudes of siblings and noir mutants at 5 and $6 \mathrm{dpf}$. $\mathbf{G}$, b-wave amplitudes of siblings and noir mutants at 5 and $6 \mathrm{dpf}$. $\boldsymbol{H}, \mathrm{d}$-wave amplitudes of siblings and noir mutants at 5 and $6 \mathrm{dpf}$.

\section{A Optokinetic Response}
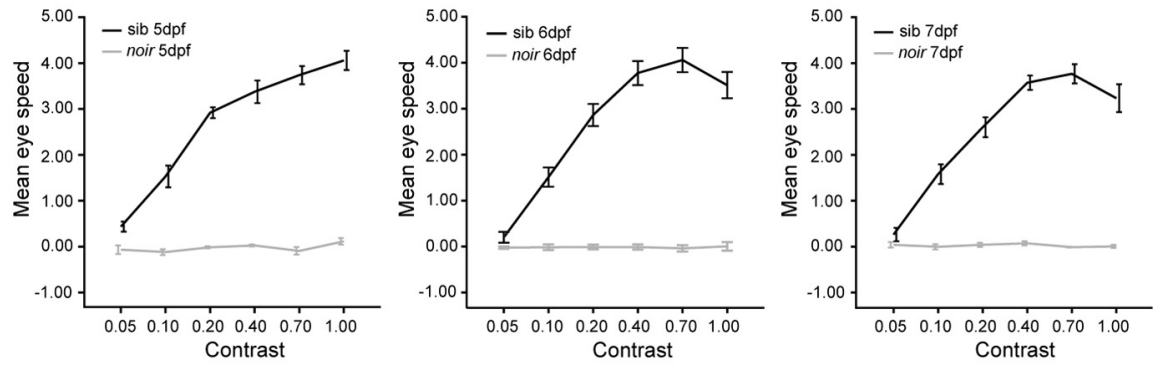

B Phototaxis

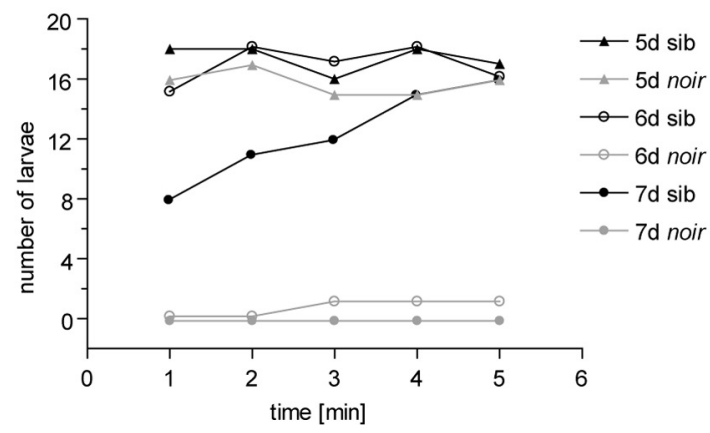

Figure 6. Visual behavior. $A$, Optokinetic response measurements of noir mutants compared with sibling larvae. The optokinetic responses were triggered by a moving grating of varying contrast. Siblings exhibit increasing eye tracking velocities with increasing contrast, whereas mutants do not show any response, despite spontaneous eye movements. Plotted are means of $n=$ $10 \pm$ SEM; the eye speed is measured in degrees per second and contrast is normalized to maximal contrast. $\boldsymbol{B}$, Phototactic behavior was assessed by a choice paradigm in which light-adapted larvae $(n=20)$ can choose between an illuminated and a dark compartment. The number of larvae in the illuminated compartment was evaluated minute-by-minute at different larval stages.
Since we detected neither an increase in apoptosis nor a different proliferation rate up to $6 \mathrm{dpf}$, we cannot distinguish between these two potential mechanisms that lead to cell count differences between mutant and sibling retinas (supplemental Fig. 2, available at www.jneurosci.org as supplemental material). However, as only a small fraction of inner retinal cells are cholinergic, a loss of these cells might be not detectable by staining for apoptosis. Nevertheless, we deem it likely that the selective loss of retinal cholinergic amacrine cells accounts for the morphological alterations found in the 6-d-old noir retina.

\section{Electroretinographic analysis of the noir retina}

A morphological change or even cell death is the final stage of a cellular defect that may very well be preceded by physiological changes apparent in a functional assay. Therefore, we recorded ERGs, sum field potentials of the retina in response to light, from 5-, 6-, and 7-d-old larvae. At 7 dpf, shortly before the whole larva dies, we were unable to evoke a retinal response (Fig. 5A-C).

The ERG composite can be deconstructed into underlying waves that reflect the function of different parts of the retina. The a-wave, the initial negative deflection, reflects photoreceptor activation and is notoriously difficult to quantify in larval zebrafish, since it interferes with the larger positive deflection of the b-wave, reflecting $\mathrm{ON}$ bipolar cell activation. Hence we pharmacologically blocked ON transmission with a mixture of the specific metabotropic glutamate receptor group III agonist (APB) and the glutamate transporters blocker (TBOA) (Grant and Dowling, 1996; Wong et al., 2004, 2005a,b) (Fig. 5D,E).

In this way, we recorded strongly diminished a-wave amplitudes, showing that photoreceptors are less sensitive to light at stages where behavioral defects but not morphological defects are apparent. Similar effects are measured for the b-wave and the d-wave, reflecting activation of the OFF response (Fig. $5 F-H$ ). The ERG deteriorates over time, probably after the depletion of maternally supplied Pdhb protein.

\section{Motion vision is selectively affected in noir larvae}

Since we recorded ERG responses at $5 \mathrm{dpf}$, a stage at which mutant larvae show no $\mathrm{OKR}$, we conclude that at $5 \mathrm{dpf}$ the lack of OKR cannot solely be attributable to de- 

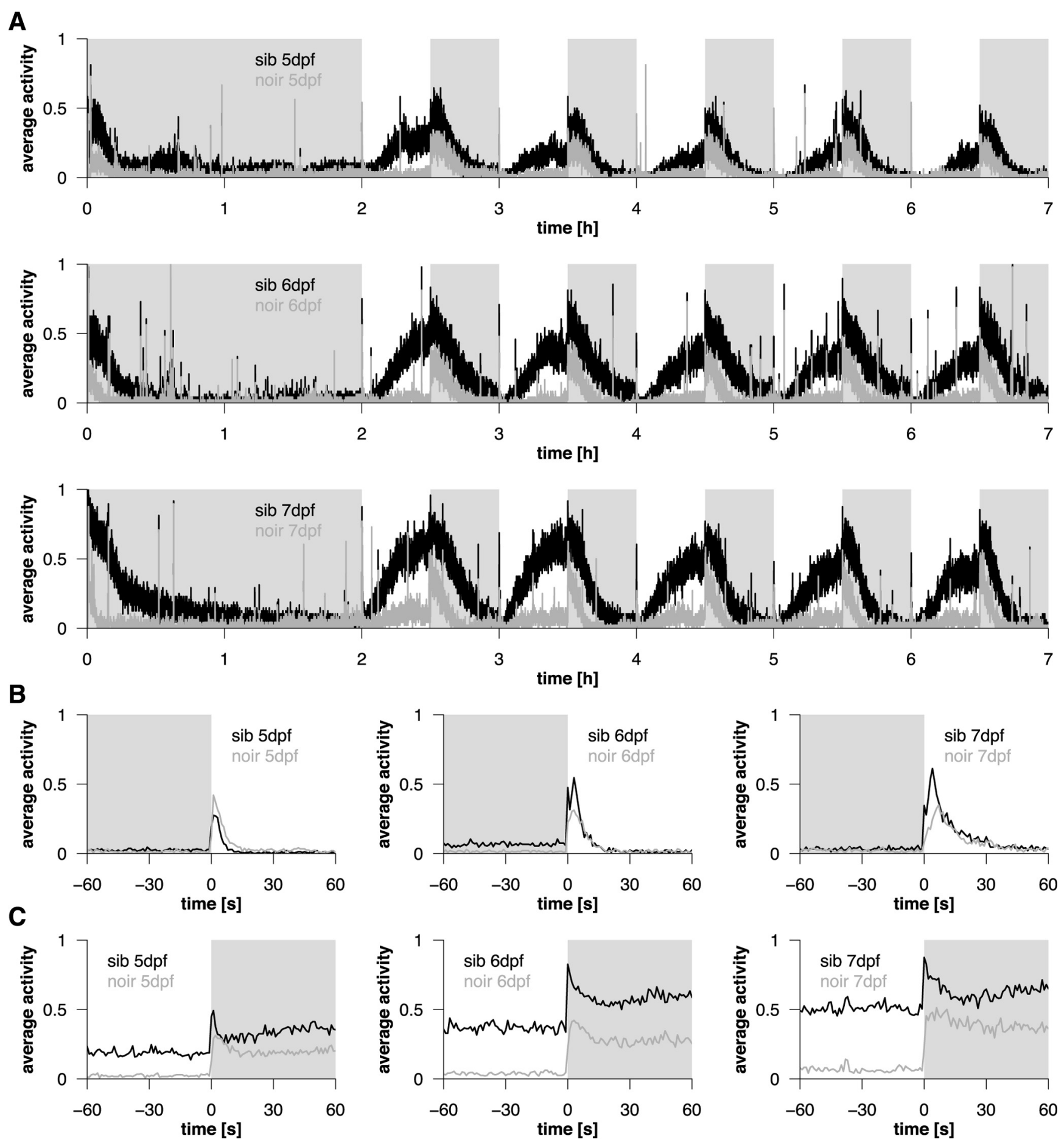

Figure 7. VMR. The VMR was assessed by tracking the locomotor activity and velocity of 48 larvae over a period of $7 \mathrm{~h}$. Lights were switched on and off every 30 min (off-periods are shaded in gray). A, Average activity during the whole tracking period is shown. $\boldsymbol{B}$, Average activity during $1 \mathrm{~min}$ before and 1 min after the $0 \mathrm{FF}-0 \mathrm{~N}$ switch (light $0 \mathrm{~N}$ response) is shown. $\boldsymbol{C}$, Average activity during $1 \mathrm{~min}$ before and $1 \mathrm{~min}$ after the $\mathrm{ON}-0 \mathrm{FF}$ switch (light OFF response) is shown.

fects in the outer retina. Hence, a motion vision-specific defect, as suggested by the reduction of cholinergic amacrine cells, may account for the complete loss of motion vision at $5 \mathrm{dpf}$. We therefore investigated visually mediated behaviors that are motion independent and first confirmed previous reports that starting at $5 \mathrm{dpf}$ no OKR can be evoked (Fig. 6A). We also recorded spontaneous eye movements, indicating that indeed a sensory problem underlies the absence of the OKR.

Since zebrafish larvae exhibit positive phototaxis (Burgess et al., 2010), this behavior can be used to test light perception inde- pendent of motion cues. We used a choice paradigm in which light-adapted larvae can choose between an illuminated and dark compartment. Both sibling and noir larvae were found to robustly swim toward the bright compartment, indicating that at 5 dpf motion detection is completely abolished but light perception is still functional. noir larvae completely lacked positive phototactic behavior at 6 and $7 \mathrm{dpf}$ (Fig. $6 \mathrm{~B}$ ). Since this assay involves swimming, we cannot exclude the possibility that swimming behavior rather than light perception is defective at these stages. Therefore, we used another visual behavior, the VMR (Emran 
A
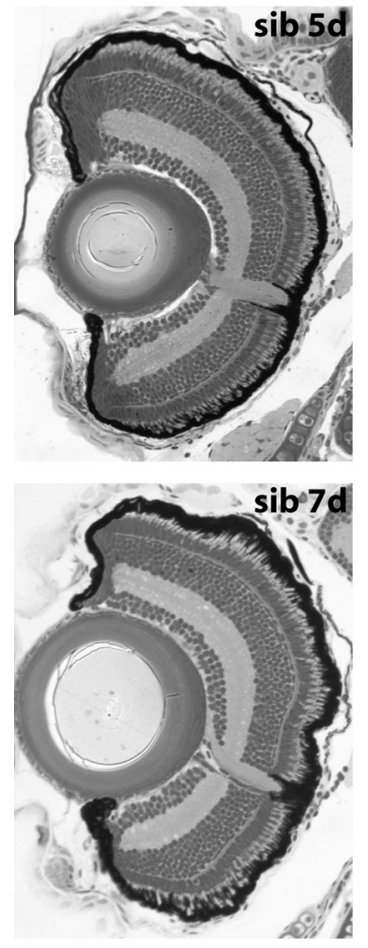
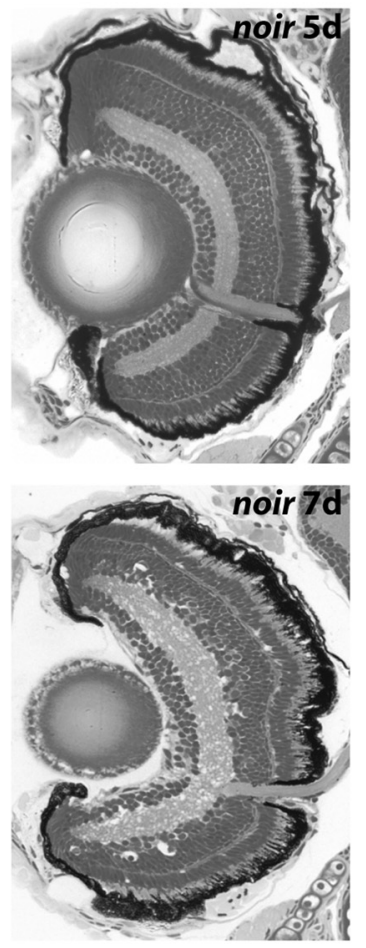

B
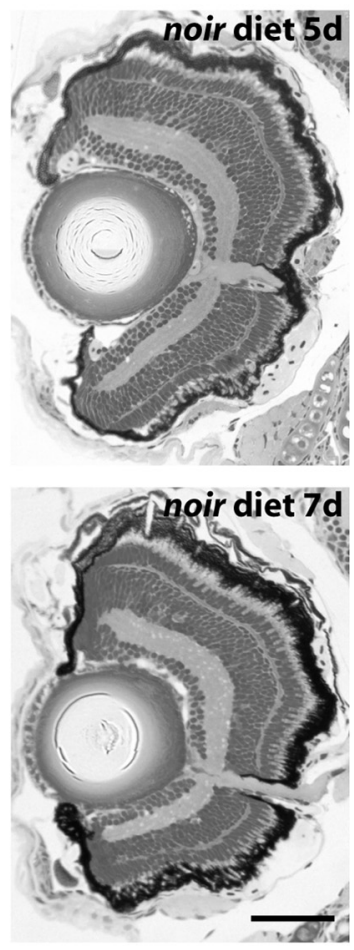

Rescue at 5dpf
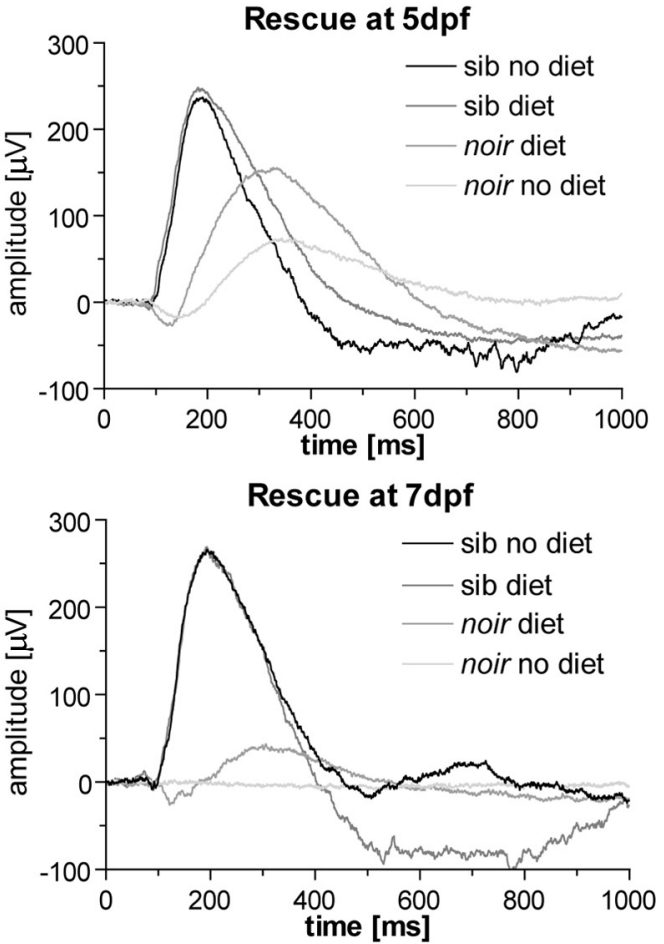

Figure 8. Ketogenic diet ameliorates the noir phenotype. $\boldsymbol{A}$, Histology of larvae raised in E3 medium containing a mixture of fatty acids is shown. Retinal morphology is improved in diet-treated mutant larvae compared with nontreated mutant larvae. Scale bar, $50 \mu \mathrm{m}$. B, Typical traces of ERG recordings of diet-treated larvae and nontreated larvae are shown. A light stimulus of 5600 lux and 100 ms was applied to elicit saturated responses.

et al., 2008), which affords less strenuous swimming. In this behavioral paradigm, the larvae's movements are tracked over time with an infrared-sensitive camera, while changing the illumination.

The overall locomotor activity of noir larvae was reduced, confirming previous observations (Fig. 7A). This reduced baseline motility can be rationalized as an energy-saving response of the larvae (Taylor et al., 2004). Another explanation for reduced locomotor activity might rest on reduced neuromuscular signaling. Signaling between nerve and muscle relies on the neurotransmitter acetylcholine (ACh), which is only available in limited amounts in the noir mutant. Similarly, the zebrafish bajan mutant, which is mutated in the acetylcholine-synthesizing enzyme ChAT, shows compromised motility and fatigue (Wang et al., 2008). We deem it likely that the reduced locomotor activity in the noir mutant is caused by a combination of reduced energy availability and decreased neuromuscular signaling. Interestingly, locomotor activity recordings show that noir larvae still react to light increments and decrements, even at $7 \mathrm{dpf}$ when no retinal activity is measurable by ERG recordings (Fig. $7 B, C$ ).

Together, these motion-independent visual behavior measurements indicate that the early loss of motion vision cannot solely be attributed to defects in the outer retina. This conclusion is also supported by the ERG results. Mutants with similar b-wave amplitudes as in $5 \mathrm{dpf}$ noir mutants are well capable to show optokinetic behavior (data not shown). In the noir mutant, at least residual light perception is preserved right until death of the larva.

\section{A ketogenic diet can rescue the noir phenotype}

Inactivation of $\mathrm{PDH}$ effectively blocks the transition from glycolysis to the TCA cycle. However such a metabolic block can be circumvented by providing the larva with fatty acids that can be used to produce acetyl-CoA independent of PDH. Such a ketogenic diet has been successfully used to rescue the phenotype of noa, a mutant defective in subunit E2 of the PDH complex (Taylor et al., 2004).

Therefore, we used a ketogenic diet for noir larvae, consisting of lauric acid, myristic acid, palmitic acid, and phosphatidyl choline. As expected, we could ameliorate the phenotype as documented by ERG and morphological analyses.

The ERG b-wave of 5-d-old untreated noir mutants has an amplitude of $\sim 80 \mu \mathrm{V}$, whereas the one of fatty acid-treated 5-dold noir mutants is increased to $\sim 150 \mu \mathrm{V}$. Similarly, at $7 \mathrm{dpf}$, untreated noir larvae exhibit a flat ERG, whereas fatty acidtreated 7-d-old noir larvae have a small ERG b-wave of $\sim 50 \mu \mathrm{V}$ (Fig. $8 B$ ). An improvement of retinal morphology was found after feeding the noir larvae with the ketogenic diet observable when comparing the retina of $7 \mathrm{dpf}$ untreated noir larvae with fatty acid-treated 7 -d-old noir larvae (Fig. $8 \mathrm{~A}$ ). Wholes in the INL and outer nuclear layer (ONL) are undetectable in these larvae. We were able to prolong survival of the noir mutants up to $14 \mathrm{~d}$.

\section{Discussion}

We have identified a mutation in the $\mathrm{E} 1 \beta$ subunit of the pyruvate dehydrogenase complex, a key enzyme in energy metabolism linking glycolysis to the TCA cycle, in the visual noir mutant. Interestingly, the phenotype starts to develop specifically in the retina by a decreased optokinetic response, reduced electrophysiological responses and morphological alterations in the inner nuclear layer. Progressively, the retinal phenotype deteriorates as evidenced by a flat ERG at day 7 and poor retinal morphology additionally affecting the outer nuclear layer (Table 1). This surprising course of phenotype progression with respect to the un- 
Table 1. Summary of the noir phenotype

\begin{tabular}{|c|c|c|c|}
\hline & $5 \mathrm{dpf}$ & $6 \mathrm{dpf}$ & $7 \mathrm{dpf}$ \\
\hline External appearance & nir darker than siblings & nir darker than siblings & nir darker than siblings \\
\hline Retinal morphology & wt-like & Cholinergic amacrine cells reduced & Multiple cell types reduced (PRCs, ACs, MCs, BPCs) \\
\hline \multirow[t]{3}{*}{ ERG } & a-wave reduced & a-wave more reduced & a-wave lost \\
\hline & b-wave reduced & b-wave lost & b-wave lost \\
\hline & $d$-wave reduced & $d$-wave more reduced & d-wave lost \\
\hline OKR & No OKR & No OKR & № OKR \\
\hline VMR & wt-like & wt-like & Slower responses \\
\hline Phototaxis & wt-like & No phototaxis & No phototaxis \\
\hline Locomotion & Locomotion reduced & Locomotion more reduced & Almost no locomotion \\
\hline
\end{tabular}

Abbreviations: wt, Wild type; PRC, photoreceptor; AC, amacrine cell; $M C$, Müller glia cell; BPC, bipolar cell.

derlying mutation in the ubiquitously expressed pyruvate dehydrogenase subunit E1 $\beta$ led us to study the noir phenotype in more detail, focusing on retinal defects.

We found that, in the noir mutant, motion-based vision is affected more severely than expected from electrophysiological measurements at $5 \mathrm{dpf}$, whereas light perception is preserved at that stage. Quantification of retinal cell types revealed that cholinergic amacrine cells are selectively damaged in the mutant inner retina, whereas other cell types are only later affected. These morphological results are corroborated by behavioral assays, showing that motion vision, as assayed by the optokinetic response, is earlier affected than light perception per se, as assayed by a phototactic assay.

Similarly, the progressive decrease of light perception is reflected by a progressive decrease in electroretinogram. Although photoreceptors show decreased light responses at $5 \mathrm{dpf}$, this reduction cannot account for the complete loss of optokinetic behavior at that stage.

Based on these observations, we propose a model in which the noir retinal phenotype is caused by two distinct mechanisms acting in parallel in the inner and the outer retina. The inner retinal defect, first apparent as a loss of motion vision, is caused by defects in cholinergic amacrine cells, whereas the outer retinal phenotype involves decreasing photoreceptor cell function.

Studies in the mammalian retina have shown that glucose consumed by photoreceptors via the choroid vasculature and retinal pigment epithelium (RPE) is not necessarily used for glycolysis and subsequent processing in the TCA cycle but is rather used to fuel the pentose phosphate pathway (PoitryYamate et al., 1995; Tsacopoulos et al., 1998). This pathway is crucial for the photoreceptor cell as it restores the levels of NADPH needed to perform the conversion of all-trans-retinal to all-trans-retinol in the photoreceptor outer segment (for review, see Saari, 2000; Muniz et al., 2007). Instead of glucose as an energy source, photoreceptors take up lactate released by Müller glia cells in large amounts, which is converted to pyruvate by lactate dehydrogenase (LDH) and subsequently fuels the TCA cycle and oxidative phosphorylation leading to ATP production. There are a number of crucial ATP-dependent reactions in the photoreceptor, including the maintenance of dark current, which requires intense pumping of $\mathrm{Na}^{+}$by the $\mathrm{Na}^{+} / \mathrm{K}^{+}$ATPase at the level of the inner segment to preserve the electrochemical gradi- ent (Steinberg, 1987; Ames et al., 1992; Okawa et al., 2008), the replenishment of GTP by ATP used to produce cGMP (Hsu and Molday, 1994), membrane renewal (Young, 1976), and powering the phototransduction process (Okawa et al., 2008). Since in the noir mutant lactate-based ATP production fails, photoreceptor cells face a lack of ATP, leading to potential deficits in all those reactions.

As a response to a hypometabolic environment, similarly to hypoxia, the photoreceptor cell may undergo metabolic suppression, which is the reduction of the principal ATP-requiring metabolic activity (Steinberg, 1987). Therefore, the question remains whether it is the limited availability of ATP that causes preventive reduced activity of the photoreceptor cell to maintain a more favorable ATP/ADP ratio, or whether the photoreceptor cell activity is impaired as a consequence of ATP lack. Since we find degeneration in the outer retina of noir mutants at later stages, the metabolic block might just have overwhelmed a potential protective mechanism of outer retinal cells, aggravated by the depletion of maternal supplies. Hence, we suggest that the noir mutant phenotype emerging in the outer retina is caused by a lack of energy in photoreceptor cells and progressively leads to vision loss in these mutants (Fig. 9).

Pathogenesis of the earlier arising phenotype in the inner retina seems to be more complex and because of its specificity unlikely to be explained by simple energy depletion.

Histology revealed a selective damage to retinal cholinergic amacrine cells (Starburst amacrine cells in the mammalian ret- 
ina), which are in the mammalian retina implicated in motiondetecting vision by giving input to DSGCs (for review, see Vaney and Taylor, 2002; Masland, 2005; Demb, 2007; Zhou and Lee, 2008). These cells release GABA and ACh simultaneously, thereby exhibiting excitatory and inhibitory properties. Although GABAergic contribution to direction selectivity is well accepted, the function of ACh release is still unresolved. A recent report by Lee et al. (2006) showed that nicotinic ACh transmission is implicated in direction selectivity. Moreover, Ackert et al. (2009) suggest a role for $\mathrm{ACh}$ in generating the $\mathrm{OFF}$ responses in $\mathrm{ON}$ DSGCs.

The existence of cholinergic amacrine cells in the zebrafish retina has been shown by several groups (Yazulla and Studholme, 2001; Arenzana et al., 2005); their functional analogy to Starburst amacrine cells of the mammalian retina, however, has not been established. Studies in the goldfish retina revealed that blockage of the nicotinic acetylcholine receptors ablates motion depending vision (Mora-Ferrer et al., 2005), suggesting a role for $\mathrm{nACh}$ receptor mediated cholinergic neurotransmission in motion perception. This hypothesis is consistent with our data, showing that the optokinetic response is abolished in noir mutants, suggesting that cholinergic amacrine cell function is impaired and subsequently these cells wither. Behavioral defects are detected earlier than morphological alterations, suggesting a sequential functional impairment of the cells followed by structural degradation.

How might acetyl-CoA depletion affect cholinergic production? We propose a model, where diminished levels of acetyl-CoA leads to diminished production of acetylcholine by the enzyme ChAT (Fig. 9). This would interfere with cholinergic signaling and possibly disturb motion perception in the noir mutant and later on lead to the ablation of cholinergic amacrine cells.

The neuromuscular circuitry, another cholinergic system, might be affected as well in the noir mutant as shown by reduced locomotion and fatigue, a phenotype also found in the zebrafish bajan mutant that has a nonfunctional ChAT enzyme (Wang et al., 2008). However, we cannot experimentally distinguish whether reduced energy or decreased neurotransmitter availability or both factors together lead to compromised locomotion in noir.

Since both manifestations of the retinal phenotype are ultimately attributable to the reduced availability of acetyl-CoA, we reasoned that providing the mutant with an alternative source should improve the defects. We could indeed ameliorate the mutant phenotype by providing the larvae with a ketogenic diet of fatty acids. This diet should result in an increase in acetyl-CoA production, bypassing the metabolic block, similar to a previous study of the noa mutant carrying a mutation in the E2 subunit of PDH (Taylor et al., 2004).

The PDH complex is located in the mitochondrial matrix and is considered to be a key metabolic enzyme. All the more does it astonish that zebrafish larvae carrying a mutation in one of the subunits of this enzyme, like noa and noir, survive to rather advanced larval stages. We have detected the existence of maternally deposited $p d h b$ mRNA in the zygote shortly after egg fertilization. With this maternal material, the embryo presumably survives the development up to day 7. Not only the diminishing maternal protein levels, but also the concomitant depletion of the yolk sac as an energy source around day 5 , enhance the sudden onset of phenotype in both the noa and the noir mutant around this age.

The longer survival of these mutants enables the study of later onset phenotypes, such as the unexpected retinal phenotype. This is in contrast to $\mathrm{PDH}$-deficient mice that are early embryonic lethal (Johnson et al., 1997, 2001).
In conclusion, the noir retinal phenotype can be described by two parallel pathogenic processes that are both caused by a deficit of acetyl-CoA.

The outer retina is affected by lack of energy, whereas the inner retinal defect is likely caused by the impaired synthesis of acetylcholine.

Our study extends previous work on the zebrafish model for PDH deficiency with a more detailed mechanism that leads to vision loss in a second animal model for PDH deficiency and might help to get a better understanding of the pathogenesis in the retina of human patients suffering from $\mathrm{PDH}$ deficiency. This mutation is a fascinating example of the deletion of a ubiquitous gene function resulting in a cell type-specific aberration.

\section{References}

Ackert JM, Farajian R, Völgyi B, Bloomfield SA (2009) GABA blockade unmasks an OFF response in ON direction selective ganglion cells in the mammalian retina. J Physiol 587:4481-4495.

Ames A 3rd, Li YY, Heher EC, Kimble CR (1992) Energy metabolism of rabbit retina as related to function: high cost of $\mathrm{Na}^{+}$transport. J Neurosci 12:840-853.

Arenzana FJ, Clemente D, Sánchez-González R, Porteros A, Aijón J, Arévalo R (2005) Development of the cholinergic system in the brain and retina of the zebrafish. Brain Res Bull 66:421-425.

Avanesov A, Dahm R, Sewell WF, Malicki JJ (2005) Mutations that affect the survival of selected amacrine cell subpopulations define a new class of genetic defects in the vertebrate retina. Dev Biol 285:138-155.

Brand M, Granato M, Nüsslein-Volhard C (2002) Keeping and raising zebrafish. In: Zebrafish: a practical approach (Nusslein-Volhard C, Dahm R, eds), pp 7-37. Oxford: Oxford UP.

Brockerhoff SE, Hurley JB, Janssen-Bienhold U, Neuhauss SC, Driever W, Dowling JE (1995) A behavioral screen for isolating zebrafish mutants with visual system defects. Proc Natl Acad Sci U S A 92:10545-10549.

Brockerhoff SE, Dowling JE, Hurley JB (1998) Zebrafish retinal mutants. Vision Res 38:1335-1339.

Burgess HA, Schoch H, Granato M (2010) Distinct retinal pathways drive spatial orientation behaviors in zebrafish navigation. Curr Biol 20: 381-386.

Cao R, Jensen LD, Söll I, Hauptmann G, Cao Y (2008) Hypoxia-induced retinal angiogenesis in zebrafish as a model to study retinopathy. PLoS One 3:e2748.

Dahm R, Geisler R., Nüsslein-Volhard C. (2005) Zebrafish (Danio rerio) genome and genetics. Weinheim, Germany: Wiley-VCH.

Demb JB (2007) Cellular mechanisms for direction selectivity in the retina. Neuron 55:179-186

Emran F, Rihel J, Dowling JE (2008) A behavioral assay to measure responsiveness of zebrafish to changes in light intensities. J Vis Exp pii:923.

Gariano RF, Gardner TW (2005) Retinal angiogenesis in development and disease. Nature 438:960-966.

Geisler R (2002) Mapping and cloning. Oxford: Oxford UP.

Grant GB, Dowling JE (1996) On bipolar cell responses in the teleost retina are generated by two distinct mechanisms. J Neurophysiol 76:3842-3849.

Haffter P, Granato M, Brand M, Mullins MC, Hammerschmidt M, Kane DA, Odenthal J, van Eeden FJ, Jiang YJ, Heisenberg CP, Kelsh RN, FurutaniSeiki M, Vogelsang E, Beuchle D, Schach U, Fabian C, Nüsslein-Volhard C (1996) The identification of genes with unique and essential functions in the development of the zebrafish, Danio rerio. Development 123:1-36.

Hsu SC, Molday RS (1994) Glucose metabolism in photoreceptor outer segments. Its role in phototransduction and in NADPH-requiring reactions. J Biol Chem 269:17954-17959.

Johnson MT, Yang HS, Magnuson T, Patel MS (1997) Targeted disruption of the murine dihydrolipoamide dehydrogenase gene $(D l d)$ results in perigastrulation lethality. Proc Natl Acad Sci U S A 94:14512-14517.

Johnson MT, Mahmood S, Hyatt SL, Yang HS, Soloway PD, Hanson RW, Patel MS (2001) Inactivation of the murine pyruvate dehydrogenase (Pdha1) gene and its effect on early embryonic development. Mol Genet Metab 74:293-302.

Kelsh RN, Brand M, Jiang YJ, Heisenberg CP, Lin S, Haffter P, Odenthal J, Mullins MC, van Eeden FJ, Furutani-Seiki M, Granato M, Hammerschmidt M, Kane DA, Warga RM, Beuchle D, Vogelsang L, Nüsslein-Volhard C 
(1996) Zebrafish pigmentation mutations and the processes of neural crest development. Development 123:369-389.

Kubota Y, Suda T (2009) Feedback mechanism between blood vessels and astrocytes in retinal vascular development. Trends Cardiovasc Med 19:38-43.

Laughlin SB (2001) Energy as a constraint on the coding and processing of sensory information. Curr Opin Neurobiol 11:475-480.

Lawson ND, Weinstein BM (2002) In vivo imaging of embryonic vascular development using transgenic zebrafish. Dev Biol 248:307-318.

Lee S, Kim K, Zhou ZJ (2006) Detection of functional cholinergic and GABAergic communications between starburst amacrine cell and direction selective ganglion cell. Invest Ophthalmol Vis Sci 47:2676.

Leigh D (1951) Subacute necrotizing encephalomyelopathy in an infant. J Neurol Neurosurg Psychiatry 14:216-221.

Makhankov YV, Rinner O, Neuhauss SC (2004) An inexpensive device for non-invasive electroretinography in small aquatic vertebrates. J Neurosci Methods 135:205-210.

Masland RH (2005) The many roles of starburst amacrine cells. Trends Neurosci 28:395-396.

McKusick VA, Kniffin CL, O’Neill MJF, Krasikov NE (1986) Leigh Syndrome; LS, MIM 256000. In: Online mendelian inheritance in man. Bethesda, MD: National Center for Biotechnology Information.

Mora-Ferrer C, Hausselt S, Schmidt Hoffmann R, Ebisch B, Schick S, Wollenberg K, Schneider C, Teege P, Jürgens K (2005) Pharmacological properties of motion vision in goldfish measured with the optomotor response. Brain Res 1058:17-29.

Mueller KP, Neuhauss SC (2010) Quantitative measurements of the optokinetic response in adult fish. J Neurosci Methods 186:29-34.

Muniz A, Villazana-Espinoza ET, Hatch AL, Trevino SG, Allen DM, Tsin AT (2007) A novel cone visual cycle in the cone-dominated retina. Exp Eye Res 85:175-184.

Neuhauss SC, Biehlmaier O, Seeliger MW, Das T, Kohler K, Harris WA, Baier H (1999) Genetic disorders of vision revealed by a behavioral screen of 400 essential loci in zebrafish. J Neurosci 19:8603-8615.

Okawa H, Sampath AP, Laughlin SB, Fain GL (2008) ATP consumption by mammalian rod photoreceptors in darkness and in light. Curr Biol 18:1917-1921.

Poitry-Yamate CL, PoitryS, Tsacopoulos M (1995) Lactate released by Muller glial cells is metabolized by photoreceptors from mammalian retina. J Neurosci 15:5179-5191.

Quintana E, Mayr JA, Garcia Silva MT, Font A, Tortoledo MA, Moliner S, Ozaez L, Lluch M, Cabello A, Ricoy JR, Koch J, Ribes A, Sperl W, Briones P (2009) PDH E(1)beta deficiency with novel mutations in two patients with Leigh syndrome. J Inherit Metab Dis. Advance online publication. Retrieved August 5, 2010. doi:10.1007/s10545-009-1343-1.

Rinner O, Rick JM, Neuhauss SC (2005) Contrast sensitivity, spatial and temporal tuning of the larval zebrafish optokinetic response. Invest Ophthalmol Vis Sci 46:137-142.

Saari JC (2000) Biochemistry of visual pigment regeneration: the Friedenwald lecture. Invest Ophthalmol Vis Sci 41:337-348.

Steinberg RH (1987) Monitoring communications between photoreceptors and pigment epithelial cells: effects of "mild" systemic hypoxia. Friedenwald lecture. Invest Ophthalmol Vis Sci 28:1888-1904.

Taylor MR, Hurley JB, Van Epps HA, Brockerhoff SE (2004) A zebrafish model for pyruvate dehydrogenase deficiency: rescue of neurological dysfunction and embryonic lethality using a ketogenic diet. Proc Natl Acad Sci U S A 101:4584-4589.

Tsacopoulos M, Poitry-Yamate CL, MacLeish PR, Poitry S (1998) Trafficking of molecules and metabolic signals in the retina. Prog Retin Eye Res 17:429-442.

Vaney DI, Taylor WR (2002) Direction selectivity in the retina. Curr Opin Neurobiol 12:405-410.

van Rooijen E, Voest EE, Logister I, Bussmann J, Korving J, van Eeden FJ, Giles RH, Schulte-Merker S (2010) von Hippel-Lindau tumor suppressor mutants faithfully model pathological hypoxia-driven angiogenesis and vascular retinopathies in zebrafish. Dis Model Mech 3:343-353.

Wallace DC (1999) Mitochondrial diseases in man and mouse. Science 283:1482-1488.

Wang M, Wen H, Brehm P (2008) Function of neuromuscular synapses in the zebrafish choline-acetyltransferase mutant bajan. J Neurophysiol 100:1995-2004.

Wong KY, Gray J, Hayward CJ, Adolph AR, Dowling JE (2004) Glutamatergic mechanisms in the outer retina of larval zebrafish: analysis of electroretinogram b-and d-waves using a novel preparation. Zebrafish 1:121-131.

Wong KY, Adolph AR, Dowling JE (2005a) Retinal bipolar cell input mechanisms in giant danio. I. Electroretinographic analysis. J Neurophysiol 93:84-93

Wong KY, Cohen ED, Dowling JE (2005b) Retinal bipolar cell input mechanisms in giant danio. II. Patch-clamp analysis of on bipolar cells. J Neurophysiol 93:94-107.

Yazulla S, Studholme KM (2001) Neurochemical anatomy of the zebrafish retina as determined by immunocytochemistry. J Neurocytol 30:551-592.

Yeo JY, Lee ES, Jeon CJ (2009) Parvalbumin-immunoreactive neurons in the inner nuclear layer of zebrafish retina. Exp Eye Res 88:553-560.

Yoshida K, Watanabe D, Ishikane H, Tachibana M, Pastan I, Nakanishi S (2001) A key role of starburst amacrine cells in originating retinal directional selectivity and optokinetic eye movement. Neuron 30:771-780.

Young RW (1976) Visual cells and the concept of renewal. Invest Ophthalmol Vis Sci 15:700-725.

Zhou ZJ, Lee S (2008) Synaptic physiology of direction selectivity in the retina. J Physiol 586:4371-4376. 